\title{
Regulation of immunity by lysosphingolipids and their G protein-coupled receptors
}

\author{
Edward J. Goetzl' ${ }^{1}$ and Hugh Rosen ${ }^{2}$
}

${ }^{1}$ Departments of Medicine and Microbiology-Immunology, UCSF, San Francisco, California, USA. 'Department of Immunology,

The Scripps Research Institute, La Jolla, California, USA.

\begin{abstract}
T and B lymphocytes, as well as endothelial cells, express distinctive profiles of G protein-coupled receptors for sphingosine 1-phosphate, which is a major regulator of $T$ cell development, $B$ and $T$ cell recirculation, tissue homing patterns, and chemotactic responses to chemokines. The capacity of drugs that act on type 1 sphingosine 1-phosphate receptors to suppress organ graft rejection in humans and autoimmunity in animal models without apparent impairment of host defenses against infections suggests that this system is a promising target for new forms of immunotherapy.
\end{abstract}

\section{Lysosphingolipids in the constellation of immunoregulatory lipids}

Lysophospholipids (LPLs) with biological mediator activity include lysoglycero-phospholipids, epitomized by lysophosphatidic acid (LPA), and lysosphingophospholipids, such as sphingosine 1-phosphate (S1P). The defining property of each LPL is an absence of 1 fatty acid from 1 of the 2 possible positions of acylation on the glycerol backbone. Both classes of LPLs share 3 important characteristics. First, their structures have a lipid domain and 1 or more polar charged substituents, and they are bound extensively in vivo by albumin and other plasma proteins. Second, they affect numerous functions of many types of cells, from proliferation and survival to migration and secretion. There is solid evidence for involvement of LPLs in processes as diverse as oxidative metabolism, angiogenesis, and carcinogenesis. Third, they all signal cells predominantly through structurally related $G$ protein-coupled receptors (GPCRs). Of the known lipid biomediators, only leukotriene $\mathrm{B}_{4}$ (LTB4), derived by 5-lipoxygenation of arachidonic acid, and S1P are considered major immune cytokines. As the effects of both S1P and LTB4 are transduced by GPCRs that are prime targets for drug development, normal and pathological contributions of the S1P and LTB4 systems are expected to be highly susceptible to pharmaceutical intervention.

All immunoregulatory lipid mediators are produced predominantly by cells of the innate immune system, such as mast cells, macrophages, and granulocytes, and act on $\mathrm{T}$ and $\mathrm{B}$ cells of the adaptive immune system, as well as phagocytes and endothelial cells, through their respective GPCRs. Arachidonic acid-derived lipid mediators, such as COX-generated prostaglandin E2 and thromboxane A2, affect some aspects of B cell and T cell development and survival, as well as cytokine secretion with low to moderate potency (1). LTB4 is a potent and selective chemotactic factor for subsets of effector $\mathrm{T}$ cells, but not for naive $\mathrm{T}$ cells, and does not effect other lymphocyte functions $(2,3)$. The phospholipid

Nonstandard abbreviations used: FTY720-P, phosphate ester of FTY720; GPCR $G$ protein-coupled receptor; HEV, high endothelial venule; LPA, lysophosphatidic acid; LPL, lysophospholipid; LTB4, leukotriene $\mathrm{B}_{4}$; PAF, platelet-activating factor; $\mathrm{S} 1 \mathrm{P}$, sphingosine 1-phosphate; SLO, secondary lymphoid organ.

Conflict of interest: Hugh Rosen is a scientific advisor to the Genomics Institute of the Novartis Foundation.

Citation for this article: J. Clin. Invest. 114:1531-1537 (2004). doi:10.1172/JCI200423704 platelet-activating factor (PAF) and PAF-like fragments of oxidized phosphatidylcholine are potent inflammatory mediators but have modest or restricted suppressive immune effects on adaptive immunity that have been recognized only in very specialized settings (4). In contrast, profound effects of S1P, LPA, and other LPLs are seen on diverse aspects of differentiation, survival, migration, tissue homing, and effector functions of mononuclear phagocytes, $\mathrm{T}$ cells, and B cells (5).

$\mathrm{S} 1 \mathrm{P}$ and its type $1 \mathrm{GPCR}$, designated $\mathrm{S} 1 \mathrm{P}$ receptor type $1\left(\mathrm{~S}_{\mathrm{P}}\right)$ constitute a system that controls thymocyte emigration into blood and the recirculation and tissue distribution of $\mathrm{T}$ and $\mathrm{B}$ cells by direct chemotactic effects. $\mathrm{S} 1 \mathrm{P}$ and $\mathrm{S}_{1} \mathrm{P}_{1}$ suppress recirculation of naive lymphocytes searching for new antigens without significant alteration of the tissue distribution of preexisting effector lymphocytes already responding to antigens. This pattern of $\mathrm{T}$ cell selectivity suggests 2 potentially unique values of therapies directed toward $\mathrm{S}_{1} \mathrm{P}_{1}$ on immune cells in the areas of transplant rejection and autoimmunity. The first is the highly specific nature of inhibition of $\mathrm{T}$ cell recruitment irrespective of the chemotactic stimulus, rather than of $T$ cell activation, and thus the possibility of combination therapy with agents that suppress principally $\mathrm{T}$ cell activation. The second is apparent avoidance of significant inhibition of host defenses, including antimicrobial activities of myelomonocytic leukocytes.

\section{Lysophospholipid GPCR families: distribution in immune cells}

LPA and S1P are present in physiological fluids in high-nanomolar to low-micromolar concentrations and have multiple effects on many types of cells (6). Initially discovered as growth factors whose actions were inhibited by pertussis toxin, LPA and S1P are now recognized to be major intracellular messengers and extracellular mediators. Cloning of the type 1 GPCR for S1P as an endothelial differentiation gene-encoded protein (7), previously termed Edg-1 and now designated $\mathrm{S}_{1} \mathrm{P}_{1}$, and the type 1 GPCR for LPA as a determinant of neurogenesis (8), previously Edg-2 and now $\mathrm{LPA}_{1}$, were landmark discoveries in the field. Subsequent cloning of rodent $\mathrm{S}_{1} \mathrm{P}_{2}$ (Edg-5) and human $\mathrm{LPA}_{2}$ (Edg-4), $\mathrm{S}_{2} \mathrm{P}_{2}$, and $\mathrm{S}_{1} \mathrm{P}_{3}$ (Edg-3) (9-11) led to rapid characterization of the remaining members of the $\mathrm{LPA}_{1-3}$ and $\mathrm{S}_{1} \mathrm{P}_{1-5}$ families and a purinergic GPCR (GPR23/ $\mathrm{LPA}_{4}$ ) that binds LPA with specificity and affinity similar to those of $\mathrm{LPA}_{1-3}$ (12). The intraspecies amino acid sequence identities 
Table 1

Cellular GPCRs for immunoregulatory LPLS

\begin{tabular}{|c|c|c|c|c|c|c|c|}
\hline \multirow[t]{2}{*}{$\begin{array}{l}\text { Formal } \\
\text { designation }\end{array}$} & \multirow[t]{2}{*}{$\begin{array}{l}\text { Colloquial } \\
\text { name }\end{array}$} & \multirow[t]{2}{*}{$\begin{array}{l}\text { Principal } \\
\text { ligands }\end{array}$} & \multirow[t]{2}{*}{$\begin{array}{l}\text { Immune cell } \\
\text { expression }\end{array}$} & \multicolumn{2}{|c|}{$\begin{array}{l}\text { Immune cell } \\
\text { functional effects }\end{array}$} & \multicolumn{2}{|c|}{$\begin{array}{c}\text { Receptor genetic and } \\
\text { pharmacological alterations }\end{array}$} \\
\hline & & & & Stimulation & Inhibition & Stimulation & Inhibition \\
\hline \multicolumn{8}{|c|}{ Edg GPCR family } \\
\hline $\mathrm{S}_{1} \mathrm{P}_{1}$ & Edg-1 & S1P & T, B, M, DCs, NK cells & Chemotaxis (S1P) & $\begin{array}{l}\text { Proliferation; } \\
\text { IFN- } \gamma \text {, IL-4 secretion; } \\
\text { chemotaxis to CKs }\end{array}$ & $\begin{array}{c}\text { FTY720-P; } \\
\text { SEW2871; } \\
\text { transgenic mouse }\end{array}$ & $\begin{array}{l}\text { FTY720; } \\
\text { KO mouse }\end{array}$ \\
\hline $\mathrm{S}_{1} \mathrm{P}_{4}$ & Edg-6 & S1P & T, B, M, NK cells & & $\begin{array}{c}\text { Proliferation; } \\
\text { IFN- } \gamma \text {, IL-4 secretion }\end{array}$ & FTY720-P & \\
\hline $\mathrm{LPA}_{2}$ & Edg-4 & LPA & $\mathrm{T}, \mathrm{B}, \mathrm{M}$ & Chemotaxis (LPA) & $\begin{array}{l}\text { Proliferation; } \\
\text { IL-2 secretion }\end{array}$ & & \\
\hline \multicolumn{8}{|c|}{ Other GPCRs for lysophospholipid mediators } \\
\hline \multirow[t]{2}{*}{ GPR65 } & TDAG8 & $\begin{array}{c}\text { PS, other } \\
\text { glycosphingolip }\end{array}$ & $\mathrm{T}, \mathrm{M}$ & $\begin{array}{l}\text { Formation of multinucle } \\
\text { glycosphingolipid globoid } \\
\text { from Ms; thymocyte apopt }\end{array}$ & & & \\
\hline & G2A & LPC, SPC & $\mathrm{T}, \mathrm{B}, \mathrm{M}$ & $\begin{array}{l}\text { Chemotaxis; } \\
\text { T cell apoptosis }\end{array}$ & & $\begin{array}{l}\text { KO mouse has } \\
\text { autoimmunity }\end{array}$ & \\
\hline GPR68 & OGR1 & $\mathrm{H}^{+}, \mathrm{SPC}$ & $\mathrm{T}$ & & Proliferation & & \\
\hline
\end{tabular}

B, B cell; CK, chemokine; Edg, endothelial differentiation gene-encoded; KO, genetically null; LPC, lysophosphatidylcholine; M, mononuclear phagocyte; PS, psychosine; SPC, sphingosylphosphorylcholine; T, T cell. FTY720 and FTY720-P, S1 $\mathrm{P}_{1}$-directed unspecific inhibitor and agonist, respectively; SEW2871 is a selective $\mathrm{S}_{1} \mathrm{P}_{1}$ GPCR agonist. Mononuclear phagocytes also express $\mathrm{S}_{1} \mathrm{P}_{3}, \mathrm{LPA}_{1}$, and LPA . B cells also express $\mathrm{S}_{1} \mathrm{P}_{3}$ and $\mathrm{LPA}$.

among the members of each respective family are $42-54 \%$ and between the LPA and S1P families are $31-36 \%$ (13). It is expected that sequence homologies among ligand-binding domains will be conserved even more, as a single glutamate-to-glutamine substitution converts high-affinity S1P binding to LPA binding of similarly high affinity (14). One basis for the diversity of effects of LPA and S1P on cells is that the GPCRs for each LPL signal through 2 or more different $G$ proteins, including: (a) $G_{i / o}$ for cellular survival, proliferation, and motility; (b) $\mathrm{G}_{12 / 13}$ for cytoskeletal remodeling and cellular shape changes; and (c) $\mathrm{G}_{\mathrm{q}}$ for a range of cellular effector functions (13). Several clusters of GPCRs that are structurally distinct from the Edg family bind biologically active LPLs other than S1P and LPA (Table 1). One of the sphingosylphosphorylcholine-binding non-Edg GPCRs, termed OGR1 (15), is also a proton sensor that links reduction in extracellular $\mathrm{pH}$ to the generation of inositol phosphates (16).

$\mathrm{T}$ and $\mathrm{B}$ cells express predominantly $\mathrm{S}_{1} \mathrm{P}_{1}, \mathrm{~S}_{1} \mathrm{P}_{4}$, and $\mathrm{LPA}_{2}$, as well as the non-Edg GPCRs TDAG8, G2A, and OGR1 (15, 17-20) (Table 1). Of the Edg GPCR family, $\mathrm{S}_{1} \mathrm{P}_{1}$ predominates quantitatively in most sets of lymphocytes at both the mRNA and protein levels, although expression and mechanisms of signal transduction differ among types of lymphocytes and in relation to their state of functional activation. $\mathrm{S} \mathrm{P}_{1}$ expressed by lymphocytes deprived of S1P are downregulated after reintroduction of S1P, but they return rapidly to the cell surface by a process involving protein kinase $\mathrm{C}-\varepsilon$ and the AP-1 transcription complex and persistently exhibit fully functional expression despite ambient concentrations of S1P ranging from subsaturating to saturating (21). Lymphocytes newly isolated from blood that contains 100-300 nM S1P and LPA not unexpectedly express functional levels of $\mathrm{S}_{1} \mathrm{P}_{1}, \mathrm{~S}_{1} \mathrm{P}_{4}$, and $\mathrm{LPA}_{2}$. Activation of $\mathrm{T}$ and $B$ cells by diverse immune stimuli and some drugs suppresses expression of $\mathrm{S}_{1} \mathrm{P}_{1}, \mathrm{~S}_{1} \mathrm{P}_{4}$, and/or $\mathrm{LPA}_{2}$ and strikingly reduces the LPL-evoked biochemical and functional signals coupled to the respective receptors $(17,18)$.

\section{Immune functional effects of S1P and its GCPR, S1P}

Although both LPA and S1P are chemotactic and moderately inhibit proliferation and the generation of some cytokines (Table 1 ), the major effect of LPL mediators on the immune system is the regulation of lymphocyte recirculation and tissue distribution by $\mathrm{S} 1 \mathrm{P}$ and $\mathrm{S}_{1} \mathrm{P}_{1}$. The specificity and effectiveness of S1P control of lymphocyte migration and circulation are determined by S1P concentration and by developmental and functional regulation of the expression of $\mathrm{S}_{1} \mathrm{P}_{1} \mathrm{GPCRs}$. In vitro, levels of $\mathrm{S} 1 \mathrm{P}$ in the range of 10-100 $\mathrm{nM}$ are sufficient to protect $\mathrm{T}$ cells from apoptosis, to enhance their chemotaxis to chemokines and other chemotactic factors, and to promote optimal activities of $\mathrm{CD} 4^{+} \mathrm{CD} 25^{+}$Tregs that are so essential for maintenance of normally balanced interactions among constituents of the immune system. Concentration gradients of S1P with means of 3-30 nM are optimally chemotactic for thymocytes and $\mathrm{T}$ and $\mathrm{B}$ cells and presumably promote both thymocyte emigration (Figure $1 \mathrm{~A}$ ) and lymphocyte movement from lymph nodes, but not spleen, back into efferent lymph and then to blood (Figure 1B) (22). Developmental upregulation of expression of $\mathrm{S}_{1} \mathrm{P}_{1}$ GPCRs is evident in the thymus (Figure $1 \mathrm{~A}$ ) (23). S1P 1 GPCRs first appear on $\mathrm{CD}^{+} \mathrm{CD}^{+}$thymocytes and subsequently attain peak levels at the $\mathrm{CD}^{+} \mathrm{CD}^{-}$and $\mathrm{CD}^{+}{ }^{+} \mathrm{CD} 4^{-}$stages just prior to emigration from the thymus (Figure 1A). Therefore, it was assumed that the major thymic effects of S1P and S1P $\mathrm{P}_{1}$ were on terminal differentiation and emigration of thymocytes into blood. This was confirmed by the finding that thymocyte sets in conditional $\mathrm{S}_{1} \mathrm{P}_{1} \mathrm{KO}$ mice with loss of $\mathrm{S} \mathrm{P}_{1}$ early in thymocyte development are normal except that they exhibited medullary hyperplasia due to retention of otherwise normal $\mathrm{CD}^{+}$and $\mathrm{CD}^{+}$ $\mathrm{T}$ cells (24). In vitro, when $\mathrm{S} 1 \mathrm{P}$ is present in concentrations ranging 300-600 nM, chemotaxis of T cells to chemokines is inhibited, which may thereby contribute to suppression of $\mathrm{T}$ cell movement from the high endothelial venule (HEV) portal of entry into lymph nodes. This also induces systemic lymphopenia in vivo in rodents, but these phenomena have not been correlated mechanistically 


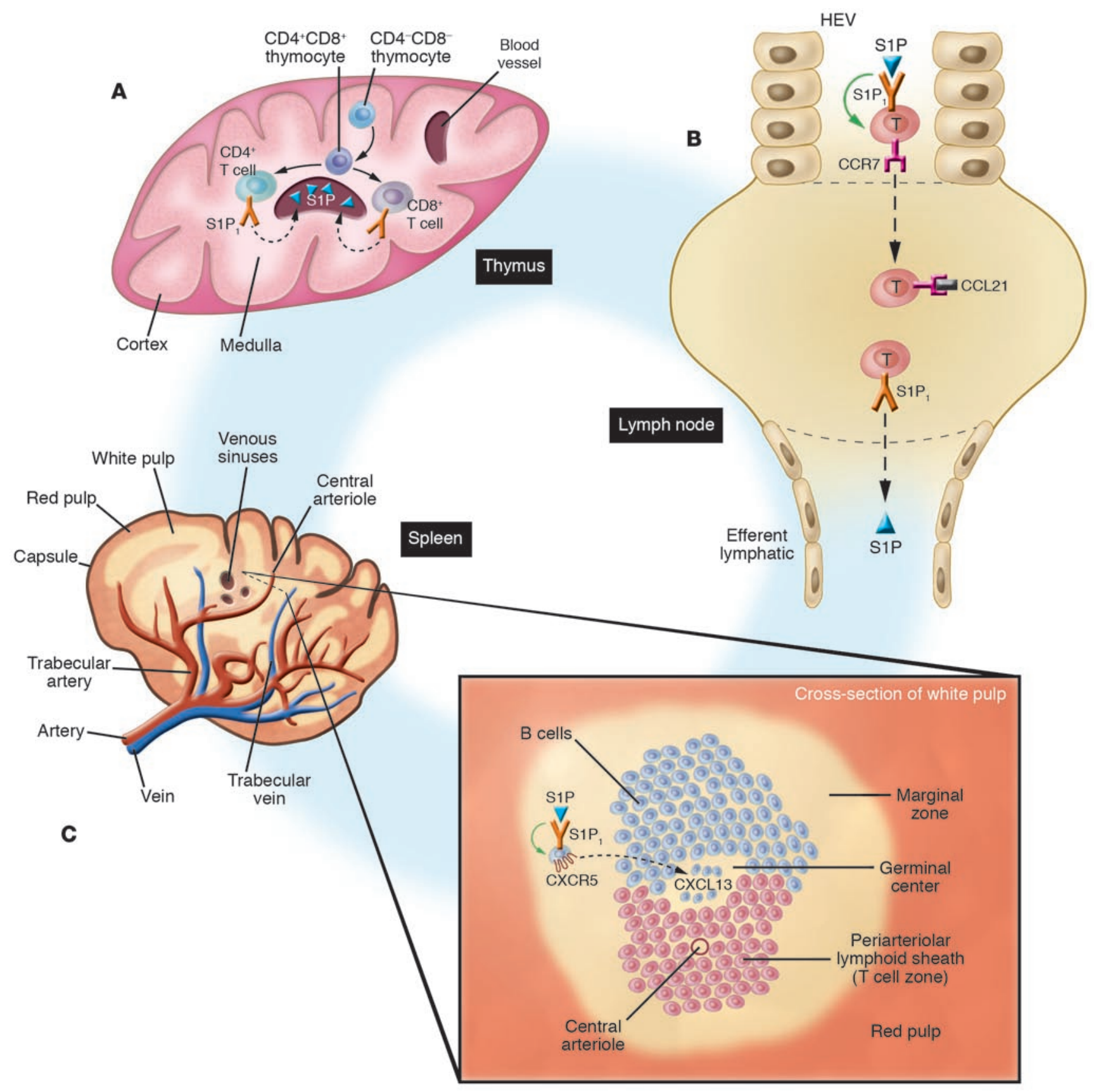

Figure 1

Control of lymphocyte development and traffic by S1P and S1P 1 . (A) Thymus. CD4-CD8- thymocytes develop into "double-positive" CD4+CD8+ thymocytes in the cortex; at the corticomedullary junction, these differentiate into CD4+ helper/inducer T cell precursors or CD8 ${ }^{+}$suppressor/ cytotoxic T cell precursors, which first express fully functional S1P 1 GPCRs. S1P in venous sinuses stimulates movement of CD4 ${ }^{+}$and CD8 $^{+}$ $\mathrm{T}$ cells out of the thymus and into the circulation. Dashed arrows show chemotaxis. (B) Lymph nodes. Plasma concentrations of S1P in the $\mathrm{HEV}$ s signal through $\mathrm{S}_{1} \mathrm{P}_{1}$, causing significant inhibition of $\mathrm{T}$ cell chemotaxis (green arrow) to chemokines such as CCL21, which attracts $\mathrm{T}$ cells through CCR7 receptors into the lymph node. T cell activation, through the T cell antigen receptor or by endotoxin, downregulates $\mathrm{S}_{1} \mathrm{P}_{1}$ GPCRs, decreases inhibition of chemotaxis, and thereby promotes chemotactic responses to chemokines with a consequent increase in $T$ cell influx into lymph nodes. In the lymph node, T cells downregulate chemokine receptors and respond chemotactically through $\mathrm{S}_{1} \mathrm{P}_{1} \mathrm{GPCR}_{\mathrm{S}}$ to the concentration gradient of S1P from the lymph node to efferent lymph, with subsequent efflux from the lymph node and reentry into the blood. Dashed arrows show chemotaxis. S1P 1 and CCR7 are both GPCRs. (C) Spleen. The white pulp of the spleen, which contains T and B cells, surrounds central arterioles coursing from trabecular arteries to veins. As shown in the cross-section of white pulp, $T$ cells are localized principally in the periarteriolar lymphoid sheath, but B cells are distributed in the germinal center, B cell corona above the germinal center, and marginal zone, where they are more quickly and completely exposed to blood-borne factors. Of all B cell locations, the concentration of S1P is predicted to be highest in the marginal zone, where it signals inhibition of B cell chemotaxis (green arrow) to the chemokine CXCL13 through its GPCR CXCR5. 
(Figure 1B). Suppression of T cell proliferation and cytokine generation also requires high physiologic levels of S1P.

$B$ cell distribution in secondary lymphoid organs (SLOs) and their recirculation into efferent lymph and then blood also are regulated by S1P and $\mathrm{S}_{1} \mathrm{P}_{1}$ (Figure $1 \mathrm{~B}$ ). B cells in the marginal zone of the spleen, which are in closer contact with blood than are B cells in the corona or germinal centers of the follicles, are presumably exposed to plasma concentrations of S1P and express $\mathrm{S}_{1} \mathrm{P}_{1}$ and $\mathrm{S}_{1} \mathrm{P}_{3}$ GPCRs (Figure 1C) (25). The inhibition of B cell chemotactic responses to germinal center chemokines, such as CXCL13, by S1P and $\mathrm{S}_{1} \mathrm{P}_{1}$ maintains $\mathrm{B}$ cells in the marginal zone. $\mathrm{B}$ cells enter the core or germinal center of a follicle in the white pulp if $\mathrm{S}_{1} \mathrm{P}_{1}$ GPCRs are eliminated genetically or suppressed sufficiently by pharmacological antagonists, in a competition analogous to that seen in lymph nodes (Figure 1, B and C). Circulating naive T and B cells, and some memory lymphocytes, express functional S1P 1 GPCRs and exhibit chemotactic and chemotactic-inhibitory responses to S1P. S1P 1 GPCR expression is downregulated in B cells and T cells activated by antigens, superantigens, and some mitogens (22). S1P and $\mathrm{S}_{1} \mathrm{P}_{1}$ consequently have far less of an effect on immune activities of effector lymphocytes than those of naive and memory sets.

\section{Pharmacological and genetic manipulation of S1P and its receptors}

The concentration of free S1P in plasma and other extracellular fluids, which determines its receptor interactions, is limited by low solubility and is tightly controlled by both protein binding and enzymatic degradation. In vivo, S1P is maintained in solution complexed to lipoproteins, most especially HDL and albumin (26). Free S1P also is rapidly degraded by abundant cell-surface lipid phosphate phosphohydrolases (27). Stringent control of free S1P concentration in physiological systems is essential because of its adverse cardiovascular effects, including bradycardia, hypotension, and coronary artery vasospasm, which are seen when plasma levels rise to as little as double the normal concentration (28-30). This steep concentration-cardiac toxicity correlation suggests that S1P is acting as a subsaturating agonist under physiological conditions and restricts studies of the role of native S1P in immunity. The use of $\mathrm{S}_{1} \mathrm{P}_{1}$-selective synthetic agonists, such as SEW2871, are now allowing researchers to study $\mathrm{S}_{1} \mathrm{P}_{1}$ regulation of lymphocyte trafficking without inducing deleterious cardiovascular effects, such as $\mathrm{S}_{1} \mathrm{P}_{3}$-mediated bradycardia (Table 1) (30-32).

Results of studies in mice in which $\mathrm{S}_{1} \mathrm{P}_{1}$ GPCRs are genetically deleted and $\mathrm{S}_{1} \mathrm{P}_{1}$-selective pharmacological agents have been applied and have recently clarified some of the roles of distinct GPCR subtypes in S1P regulation of immune cell trafficking. In addition to affecting $\mathrm{S}_{1} \mathrm{P}_{1}$ GPCRs, each experimental approach perturbs the spectrum of S1P GPCRs in different ways and with distinctive specificity. Some of the findings from pharmacological studies appear inconsistent with those from genetic analyses, and these issues will be addressed below. Investigations of the mechanisms of clinical immunosuppression by the novel drug FTY720, which is a sphingosine analog phosphorylated by sphingosine kinase 2, first implicated S1P systems in the regulation of lymphoid cell traffic in vivo (33-36). The phosphate ester of FTY720 (FTY720-P) is a true agonist of nanomolar potency for $\mathrm{S}_{1} \mathrm{P}_{1}$, $\mathrm{S}_{1} \mathrm{P}_{3}, \mathrm{~S}_{1} \mathrm{P}_{4}$, and $\mathrm{S}_{1} \mathrm{P}_{5}$, but not $\mathrm{S}_{\mathrm{P}} \mathrm{P}_{2}(37)$, and most components of FTY720-mediated immunosuppression can be replicated by nonhydrolysable phosphonate analogs of FTY720 (38). Unphosphorylated FTY720, which may be processed in target cells, has a prolonged downregulating activity for $\mathrm{S}_{1} \mathrm{P}_{1}, \mathrm{~S}_{1} \mathrm{P}_{2}$, and $\mathrm{S}_{1} \mathrm{P}_{5}$, but not $\mathrm{S}_{1} \mathrm{P}_{4}$ or $\mathrm{S}_{1} \mathrm{P}_{3}$, with minimal agonist effect (39).

In rodents, FTY720 consistently and selectively suppresses the levels of lymphocytes in blood and lymphatic fluid by $70-90 \%$ and concurrently elicits sequestration of recirculating B and T lymphocytes in SLOs within 2 hours of administration (35). Naive lymphocytes, as well as some lymphocytes responding to viral and peptide antigens in SLOs $(40,41)$, are preferentially sequestered in mesenteric and peripheral lymph nodes, as well as Peyer's patches, but never in spleen. Spleen size actually declines over time with FTY720 administration (42). The trapping of effector T cells by FTY720 requires that these cells reside in lymph nodes, and differentiated $\mathrm{CD} 4^{+} \mathrm{T}$ cells already circulating in blood are not sequestered in SLOs $(40,43)$. Lymph node lymphocytes are acutely sequestered by accumulation subjacent to lining endothelium of lymphatic sinuses, in which lymphocytes are not seen. Disappearance of lymphocytes from thoracic duct lymph precedes their disappearance from blood (35). All effects of FTY720 on lymphocyte circulation and sequestration, including histological evidence of sequestration in lymph nodes, were recently induced and maintained with an agonist selective for $\mathrm{S}_{1} \mathrm{P}_{1}$ alone (30). In the thymus, $\mathrm{S}_{1} \mathrm{P}_{1}$ agonists promote late-stage phenotypic maturation of medullary $\mathrm{CD}^{+}$and $\mathrm{CD}^{+}$thymocytes; reduce their expression of surface protein markers of activation, such as CD69, which has a C-type lectin domain postulated to facilitate normal thymocyte traffic; and inhibit thymocyte emigration into blood (Figure 1A) (44). An analog of FTY720-P, designated AAL(R), exhibits these activities at picomolar free plasma concentrations and likely at low receptor occupancy (44). Chronic administration of FTY720-P led to cortical thinning and medullary thickening of rodent thymus with medullary accumulation of $\mathrm{CD}^{+}$and $\mathrm{CD} 8^{+} \mathrm{T}$ cells lacking surface CD69 (45). Thymocyte emigration into blood and T cell egress from lymph nodes into efferent lymph both require expression of the CCR7 chemokine GPCR, as well as the S1P 1 GPCR (Figure 1, A and B). Histological data show that FTY720-induced sequestration of lymphocytes occurs at a point upstream of the mediation of $T$ cell traffic through lymph nodes by CCR7 and $\mathrm{S}_{1} \mathrm{P}_{1}$, since defective $\mathrm{T}$ and $\mathrm{B}$ cell homing to lymph nodes was rescued by FTY720 administration in both $\mathrm{Ccr}^{-1-}$ mice and plt mice, which lack relevant functional chemokines (46).

Genetic approaches to $\mathrm{S}_{1} \mathrm{P}_{1}$ deletion have included reconstitution of lethally irradiated wild-type mice with fetal liver cells from $\mathrm{S}_{1} \mathrm{P}_{1}$-KO mice and selective deletion of $\mathrm{S} \mathrm{P}_{1}{ }^{+}$early thymocytes and all subsequent $\mathrm{T}$ cell stages in lck-cre conditional $\mathrm{KO}$ mice $(23,24)$. In both models, $\mathrm{S}_{1} \mathrm{P}_{1}$-null thymocytes did not emigrate from the thymus (Figure 1A), the numbers of mature thymocytes in the thymus were increased, and there were no $\mathrm{S}_{1} \mathrm{P}_{1}$-null $\mathrm{T}$ cells in blood, lymph nodes, spleen, or nonlymphoid organs. Fluorescence-labeled $\mathrm{S}_{1} \mathrm{P}_{1}$-null $\mathrm{T}$ cells, which were adoptively transferred into wild-type mice, showed strikingly diminished egress from SLOs (Figure 1B). The total number of $\mathrm{S}_{1} \mathrm{P}_{1}$-null $\mathrm{B}$ cells in peripheral lymphoid organs was normal, but systemic defects in their distribution included decreased mature B cells in bone marrow, an abnormally low percentage of B cells in blood, and a reduction in egress from SLOs, suggestive of impaired recirculation similar to that of $\mathrm{T}$ cells. $\mathrm{S}_{1} \mathrm{P}_{1}$-dependent differences also were observed in $\mathrm{B}$ cell distribution in the spleen (Figure 1C). Chemokine-driven movement of $\mathrm{B}$ cells from the marginal zone to follicles of the spleen was lost in mice with disrupted chemokine systems and inhibited by $\mathrm{S} 1 \mathrm{P}$ and $\mathrm{S}_{1} \mathrm{P}_{1}$, which was confirmed by $\mathrm{B}$ cell move- 
ment into the follicles when $\mathrm{S}_{1} \mathrm{P}_{1}$ was deleted genetically or antagonized pharmacologically (Figure 1C) (25). A recently described model of $\mathrm{T}$ cell-selective transgenic overexpression of $\mathrm{S}_{1} \mathrm{P}_{1}$ GPCRs and resistance to their activation-induced downregulation showed increased numbers of $\mathrm{T}$ cells in the blood and prolonged $\mathrm{T}$ cell circulation and residence in blood, due to decreased entry into SLOs (47). The consequent impairment of the interaction of T cells with antigens in SLOs eliminates cutaneous delayed-type hypersensitivity and suppresses IgG antibody responses.

Both genetically and pharmacologically induced alterations in $\mathrm{S}_{1} \mathrm{P}_{1}$ expression or function inhibit emigration of $\mathrm{CD}^{+}$and $\mathrm{CD}^{+}$ thymocytes $(23,44)$. However, CD69 on thymocytes is upregulated by $\mathrm{S}_{1} \mathrm{P}_{1}$ gene deletion and downregulated by $\mathrm{S}_{1} \mathrm{P}_{1}$-suppressing drugs. The mechanisms of genetic and pharmacological suppres-

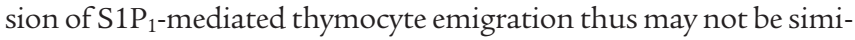
lar, as suggested by their differential effects on CD69 expression in thymocyte emigration (48). The abnormal sequestration in SLOs of adoptively transferred $\mathrm{T}$ and $\mathrm{B}$ cells genetically deficient in $\mathrm{S}_{\mathrm{P}}$ resembles the effects of FTY720 on wild-type T cells and B cells, but their localization in spleen as well as Peyer's patches distinguishes them from lymphocytes treated with FTY720 or related agonists, which do not home to spleen. $\mathrm{S}_{1} \mathrm{P}_{1}$ gene deletion studies clearly support a role for lymphocytic $\mathrm{S}_{1} \mathrm{P}_{1}$ in development, circulation, and lymphoid tissue distribution of naive lymphocytes (Figure 1, A-C). However, it is premature to closely compare results of genetic deletion to those from studies using pharmacological agents because they likely differ in many mechanistic details. It may be, for example, that these approaches differ in some effects on lymphocyte trafficking because of distinct alterations of stromal cell functions relevant to migration or homing. The lack of effect of FTY720 and related compounds on $\mathrm{T}$ cell sequestration in the spleen cannot be explained by differences in lymphocyte $\mathrm{S}_{1} \mathrm{P}_{1}$ GPCR expression alone, given the similarities in naive $\mathrm{T}$ cell populations observed in spleen, lymph nodes, Peyer's patches, and blood. Further studies will be required to determine how the mechanisms of S1P agonism and downregulation of immune cell S1P 1 GPCRs (39) together regulate alterations in lymphocyte trafficking.

\section{S1P receptors in animal models of disease}

Investigations of the effects of $\mathrm{S}_{1} \mathrm{P}_{1} \mathrm{GPCR}$-active agents in animal models of human diseases have yielded considerable data suggesting that $\mathrm{S} 1 \mathrm{P}$ and $\mathrm{S}_{1} \mathrm{P}_{1}$ control abnormal as well as physiologic lymphocyte behavior. Much of this information initially came from evaluation of the therapeutic benefit of FTY720 for primary prevention of renal allograft rejection (49). Alterations of numerous aspects of lymphocyte development, circulation, tissue migration, and function by FTY720 also prevents T cell access to and damage of heart, lungs, intestines, kidneys, and brain in transplantation rejection and diverse autoimmune diseases. S1P 1 GPCR-active agents act synergistically with lower-than-conventional doses of other immunosuppressive agents, such as cyclosporine A, and minimize their toxicities without apparent additional impairment of intrinsic lymphocyte or myeloid defense functions (34). Further studies of effects of $\mathrm{S}_{1} \mathrm{P}_{1}$ GPCR-active agents alone and in combination with other immunosuppressive drugs on host defenses against microbial infections are necessary.

S1P-like agonists prolong renal, heart, and skin organ engraftment in rodents, dogs, cynomolgus monkeys, and humans (50-53). Drug-induced tolerance - which here refers to the set of immunological regulatory mechanisms evoked by a graft during immunosuppressive therapy and able to promote graft survival after cessation of this therapy - remains intact or is enhanced by FTY720 treatment in rodents. Differential effects of FTY720 on the traffic of engrafted rodent lymphocytes are end organ dependent, so that there may be inhibition of graft-versus-host disease - as, for example, suppression of lymphocyte destruction of intestinal epithelium - without suppression of graft cytotoxicity for a concurrently transferred lymphoma restricted to lymph nodes (54). In addition, responses to systemic infectious antigens such as lymphocytic choriomeningitis virus remain quantitatively intact, although distributed anomalously in lymph nodes and Peyer's patches but not spleen, and are accompanied by normal antibody responses and memory to vesicular stomatitis virus infection (41). Through its potent T cell effects, FTY720 is an effective immunosuppressant in models of immune-mediated tissue damage, including collagen-induced arthritis, experimental autoimmune encephalomyelitis, pancreatic islet destruction, lymphoproliferation, nephrotic syndrome in $l \mathrm{pr}^{-1-}$ mice, and numerous other autoimmune disease models (55-58).

Retention of healthy foreign tissue grafts thus can be facilitated and autoimmune tissue damage minimized by prophylactic manipulation of the S1P-S1P 1 GPCR system. However, the possibilities for successful intervention in autoimmunity after disease inception, when many effector $\mathrm{T}$ cells are already in blood and tissue compartments, remain uncertain. This is particularly a concern given the lack of sequestration by FTY720 of circulating CD4 ${ }^{+} \mathrm{T}$ cells already polarized into Th1 and Th2 types $(40,43)$. S1 $\mathrm{P}_{1}$-dependent sequestration of lymphocytes may therefore be an effective approach to sustained therapy for autoimmune diseases only in combination with drugs that act by other mechanisms capable of removing or suppressing preexisting effector T cells. Another possible application might be an induction-maintenance paradigm, where other drugs inhibit the contribution of circulating effector $\mathrm{T}$ cells from blood and sites of active autoimmune tissue damage before FTY720 prevents entry of other T cells to the sites.

\section{Implications for immunoregulation in humans}

As each type of immune cell so far examined expresses a distinctive complement of GPCRs for S1P (Table 1), which have central roles in mobilization, recruitment, and specific immune functions, it is not surprising that pharmacological agonists and antagonists specific for these GPCRs will substantially alter both normal and abnormal immunity. Results of studies of the effects of FTY720 have provided a preview of the enormous therapeutic potential of such agents, as it inhibits development of numerous $\mathrm{T}$ cell-dependent autoimmune diseases in animal models and suppresses rejection of organ transplants in humans with little deleterious impact on host defenses against infections. Further advances will depend on several points of focus beyond a greater understanding of the complex effects of S1P and $\mathrm{S}_{1} \mathrm{P}_{1}$ in immune biology. The first step should be the production of potent agonists and antagonists selective for individual GPCRs. Polyspecific FTY720-P binds to $\mathrm{S}_{1} \mathrm{P}_{3}$ GPCRs of antigen-presenting and cardiac cells, as well as to $\mathrm{S}_{1} \mathrm{P}_{1}$ GPCRs of naive $\mathrm{T}$ cells, so that it is not possible to tightly focus therapeutic benefits with a broad composite activity profile. The second should include greater attention to the timing of application of $\mathrm{S}_{1} \mathrm{P}_{1}$ GPCRactive agents, which may be a major determinant of maximizing suppression of abnormal immune reactions and minimizing deleterious suppression of normal responses. Persistent prophy- 
laxis with FTY720 may be optimal for suppression of transplant rejection, but limiting administration to, for example, early recurrences of multiple sclerosis is likely to be more effective, as it avoids impairing natural autoimmune suppressive activities of $\mathrm{CD} 4^{+} \mathrm{CD} 25^{+}$Tregs during remissions. The third step should include a more careful definition of the actions of the S1P-S1P

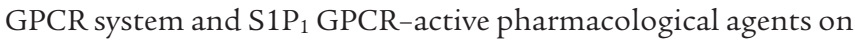
antibody production. Significantly reduced IgG and heightened IgE antibody responses to simple antigens were found in transgenic mice expressing $\mathrm{T}$ cell levels of $\mathrm{S}_{1} \mathrm{P}_{1}$ GPCRs only moderately higher than normal (47). These results have suggested possible benefits of $\mathrm{S}_{1} \mathrm{P}_{1}$-directed pharmacological agonists in the treatment of autoimmune diseases mediated principally by antibodies to self antigens. The fourth step needed is to define nonimmune and possibly deleterious side effects of manipulating any ligandreceptor complex that is distributed and active in every organ system. The elicitation of sinus bradycardia by FTY720 is one warning of such possibilities, which hopefully will be avoided by greater selectivity of agents for the $\mathrm{S}_{1} \mathrm{P}_{1}$ GPCRs.

Ongoing basic research directed at better understanding of the immunological roles of the S1P ligand-S1 $\mathrm{P}_{1}$ GPCR system has led to characterization of the most active immunoregulatory lipid mediator known and revealed a major new avenue of immunosuppression based on highly selective alterations in lymphocyte development, recycling, and tissue traffic. The fundamental therapeutic challenge is to design protocols in which alterations of the selectively immunoregulatory S1P-S1P ${ }_{1}$ GPCR system have optimal beneficial effects in diseases caused by multiple complex immunological abnormalities. The most apparent value of this approach is a far more favorable toxicity profile than those of broader-acting immunosuppressive drugs. If $\mathrm{S}_{1} \mathrm{P}_{1} \mathrm{GPCR}$-active drugs are not alone sufficiently effective to suppress transplant rejection and autoimmunity, then it is hoped that addition of low doses of conventional agents in combination regimens will allow immunosuppression that is less toxic than the high doses of existing drugs.

\section{Acknowledgments}

These studies were supported by NIH grants HL31809 (to E.J. Goetzl) and AI055509 (to H. Rosen).

Address correspondence to: Edward J. Goetzl, University of California, Room UB8B, UC Box 0711, 533 Parnassus at 4th, San Francisco, California 94143-0711, USA. Phone: (415) 476-5339; Fax: (415) 476-6915; E-mail: egoetzl@itsa.ucsf.edu.
1. Goetzl, E.J., An, S., and Smith, W.L. 1995. Specificity of expression and effects of eicosanoid mediators in normal physiology and human diseases. FASEB J. 9:1051-1058.

2. Goodarzi, K., Goodarzi, M., Tager, A.M., Luster, A.D., and von Andrian, U.H. 2003. Leukotriene B4 and BLT1 control cytotoxic effector T cell recruitment to inflamed tissues. Nat. Immunol. 4:965-973.

3. Tager, A.M., et al. 2003. Leukotriene B4 receptor BLT1 mediates early effector $\mathrm{T}$ cell recruitment. Nat. Immunol. 4:982-990.

4. Walterscheid, J.P., Ullrich, S.E., and Nghiem, D.X. 2002. Platelet-activating factor, a molecular sensor for cellular damage, activates systemic immune suppression. J. Exp. Med. 195:171-179.

5. Tigyi, G., and Goetzl, E.J. 2002. Lysolipid mediators in cell signaling and disease. Biochim. Biophys. Acta. 1582:vii.

6. Goetzl, E.J., and Lynch, K.R. 2000. Lysophospholipids and eicosanoids in biology and pathophysiology. Ann. N. Y. Acad. Sci. 905:1-357.

7. Hla, T., and Maciag, T. 1990. An abundant transcript induced in differentiating human endothelial cells encodes a polypeptide with structural similarities to G-protein-coupled receptors. J. Biol. Chem. 265:9308-9313.

8. Hecht, J.H., Weiner, J.A., Post, S.R., and Chun, J. 1996. Ventricular zone gene-1 (vzg-1) encodes a lysophosphatidic acid receptor expressed in neurogenic regions of the developing cerebral cortex. J. Cell Biol. 135:1071-1083.

9. Maclennan, A.J., Marks, L., Gaskin, A.A., and Lee, N. 1997. Embryonic expression pattern of H218, a G-protein coupled receptor homolog, suggests roles in early mammalian nervous system development. Neuroscience. 79:217-224.

10. An, S., Bleu, T., Hallmark, O.G., and Goetzl, E.J. 1998. Characterization of a novel subtype of human $\mathrm{G}$ protein-coupled receptor for lysophosphatidic acid. J. Biol. Chem. 273:7906-7910.

11. An, S., et al. 1997. Identification of cDNAs encoding two $G$ protein-coupled receptors for lysosphingolipids. FEBS Lett. 417:279-282.

12. Noguchi, K., Ishii, S., and Shimizu, T. 2003. Identification of $\mathrm{p} 2 \mathrm{y} 9 / \mathrm{GPR} 23$ as a novel $\mathrm{G}$ proteincoupled receptor for lysophosphatidic acid, structurally distant from the Edg family. J. Biol. Chem. 278:25600-25606.
13. Chun, J., et al. 2002. International Union of Pharmacology. XXXIV. Lysophospholipid Receptor Nomenclature. Pharmacol. Rev. 54:265-269.

14. Wang, D.A., et al. 2001. A single amino acid determines lysophospholipid specificity of the S1P1 (EDG1) and LPA1 (EDG2) phospholipid growth factor receptors. J. Biol. Chem. 276:49213-49220.

15. Xu, Y., et al. 2000. Sphingosylphosphorylcholine is a ligand for ovarian cancer G-protein-coupled receptor 1. Nat. Cell Biol. 2:261-267.

16. Ludwig, M.G., et al. 2003. Proton-sensing G-protein-coupled receptors. Nature. 425:93-98.

17. Zheng, Y., Voice, J.K., Kong, Y., and Goetzl, E.J. 2000. Altered expression and functional profile of lysophosphatidic acid receptors in mitogenactivated human blood T lymphocytes. FASEB J. 14:2387-2389

18. Graeler, M., and Goetzl, E.J. 2002. Activationregulated expression and chemotactic function of sphingosine 1-phosphate receptors in mouse splenic T cells. FASEB J. 16:1874-1878.

19. Im, D.S., Heise, C.E., Nguyen, T., O’Dowd, B.F., and Lynch, K.R. 2001. Identification of a molecular target of psychosine and its role in globoid cell formation. J. Cell Biol. 153:429-434.

20. Kabarowski, J.H., Zhu, K., Le, L.Q., Witte, O.N., and $\mathrm{Xu}$, Y. 2001. Lysophosphatidylcholine as a ligand for the immunoregulatory receptor G2A. Science. 293:702-705.

21. Graeler, M.H., Kong, Y., Karliner, J.S., and Goetzl, E.J. 2003. Protein kinase C epsilon dependence of the recovery from down-regulation of S1P1 G protein-coupled receptors of T lymphocytes. J. Biol. Chem. 278:27737-27741.

22. Goetzl, E.J., and Graler, M.H. 2004. Sphingosine 1-phosphate and its type $1 \mathrm{G}$ protein-coupled receptor: trophic support and functional regulation of T lymphocytes. J. Leukoc. Biol. 76:30-35.

23. Matloubian, M., et al. 2004. Lymphocyte egress from thymus and peripheral lymphoid organs is dependent on S1P receptor 1. Nature. 427:355-360.

24. Allende, M.L., Dreier, J.L., Mandala, S., and Proia, R.L. 2004. Expression of the sphingosine 1-phosphate receptor, S1P1, on T-cells controls thymic emigration. J. Biol. Chem. 279:15396-15401.

25. Cinamon, G., et al. 2004. Sphingosine 1-phosphate receptor 1 promotes $B$ cell localization in the splenic marginal zone. Nat. Immunol. 5:713-720.
26. Murata, N., et al. 2000. Interaction of sphingosine 1-phosphate with plasma components, including lipoproteins, regulates the lipid receptor-mediated actions. Biochem. J. 352:809-815.

27. Mandala, S.M., et al. 2000. Molecular cloning and characterization of a lipid phosphohydrolase that degrades sphingosine-1- phosphate and induces cell death. Proc. Natl. Acad. Sci. U. S. A. 97:7859-7864

28. Liliom, K., et al. 2001. Sphingosylyphosphocholine is a naturally occurring lipid mediator in blood plasma: a possible role in regulating cardiac function via sphingolipid receptors. Biochem. J. 355:189-197.

29. Dantas, A.P.V., Igarashi, J., and Michel, T. 2003. Sphingosine 1-phosphate and control of vascular tone. Am. J. Physiol. Heart Circ. Physiol. 284:H2045-H2052.

30. Sanna, M.G., et al. 2004. Sphingosine 1-phosphate (S1P) receptor subtypes $\mathrm{S} 1 \mathrm{P} 1$ and $\mathrm{S} 1 \mathrm{P} 3$, respectively, regulate lymphocyte recirculation and heart rate. J. Biol. Chem. 279:13839-13848.

31. Forrest, M., et al. 2004. Immune cell regulation and cardiovascular effects of sphingosine 1-phosphate receptor agonists in rodents are mediated via distinct receptor subtypes. J. Pharmacol. Exp. Ther. 309:758-768.

32. Hale, J.J., et al. 2004. Selecting against S1P(3) enhances the acute cardiovascular tolerability of 3(N-benzyl)aminopropylphosphonic acid S1P receptor agonists. Bioorg. Med. Chem. Lett. 14:3501-3505.

33. Chiba, K., et al. 1996. FTY720, a novel immunosuppressant possessing unique mechanisms. I. Prolongation of skin allograft survival and synergistic effect in combination with cyclosporine in rats. Transplant. Proc. 28:1056-1059.

34. Chiba, K., et al. 1999. FTY720, a novel immunosuppressant, induces sequestration of circulating lymphocytes by acceleration of lymphocyte homing. Transplant. Proc. 31:1230-1233.

35. Mandala, S., et al. 2002. Alteration of lymphocyte trafficking by sphingosine-1-phosphate receptor agonists. Science. 296:346-349.

36. Sanchez, T., et al. 2003. Phosphorylation and action of the immunomodulator FTY720 inhibits vascular endothelial cell growth factor-induced vascular permeability. J. Biol. Chem. 278:47281-47290.

37. Brinkmann, V., et al. 2002. The immune modulator FTY720 targets sphingosine 1-phosphate receptors. J. Biol. Chem. 277:21453-21457. 
38. Hale, J.J., et al. 2004. Potent S1P receptor agonists replicate the pharmacologic actions of the novel immune modulator FTY720. Bioorg. Med. Chem. Lett. 14:3351-3355.

39. Graler, M.H., and Goetzl, E.J. 2004. The immunosuppressant FTY720 down-regulates sphingosine 1-phosphate G-protein-coupled receptors. FASEB J. 18:551-553.

40. Xie, J., Nomura, N., Quackenbush, E., Forrest, M. and Rosen, H. 2003. Sphingosine-1-phosphate receptor agonists impair the efficiency of the local immune response by altering trafficking of naive and antigen-activated CD4+ T cells. J. Immmunol. 170:3662-3670.

41. Pinschewer, D.D., et al. 2000. FTY720 immunosuppression impairs effector T-cell peripheral homing without affecting induction, expansion, and memory. J. Immunol. 164:5761-5770.

42. Chiba, K., et al. 1998. FTY720, a novel immunosuppressant, induces sequestration of circulating mature lymphocytes by acceleration of lymphocyte homing in rats. I. FTY720 selectively decreases the number of circulating mature lymphocytes by acceleration of lymphocyte homing. J. Immunol. 160:5037-5044.

43. Sawicka, E., et al. 2003. Inhibition of Th1- and Th2mediated airway inflammation by the sphingosine 1-phosphate receptor agonist FTY720. J. Immunol. 171:6206-6214.

44. Rosen, H., Alfonso, C., Surh, C.D., and McHeyzer-
Williams, M.G. 2003. Rapid induction of medullary thymocyte phenotypic maturation and egress inhibition by nanomolar sphingosine 1-phosphate receptor agonist. Proc. Natl. Acad. Sci. U. S. A. 100:10907-10912.

45. Yagi, H., et al. 2000. Immunosuppressant FTY720 inhibits thymocyte emigration. Eur. J. Immunol. 30:1435-1444.

46. Henning, G., et al. 2001. CCR7-dependent and -independent pathways for lymphocyte homing: modulation by FTY720. J. Exp. Med. 194:1875-1881.

47. Graler, M.H., and Goetzl, E.J. 2004. Expression and function of the type 1 sphingosine 1-phosphate receptor $\left(\mathrm{S}_{\mathrm{P}} \mathrm{P}_{1} \mathrm{-}\right)$ in immunity. In International Proceedings of Immunology 2004. Medimond S.r.l. Bologna, Italy. 49-52.

48. Nakayama, T., et al. 2002. The generation of mature, single-positive thymocytes in vivo is dysregulated by CD69 blockade or overexpression. J. Immunol. 168:87-94.

49. Brinkmann, V., and Lynch, K. 2002. FTY720: targeting G-protein-coupled receptors for S1P in transplantation and autoimmunity. Curr. Opin. Immunol. 14:569-575.

50. Chueh, S.C., et al. 1997. Induction of tolerance toward rat cardiac allografts by treatment with allochimeric class I MHC antigen and FTY720. Transplantation. 64:1407-1414.

51. Suzuki, S., et al. 1998. An immunosuppressive regimen using FTY720 combined with cyclospo- rin in canine kidney transplantation. Transpl. Int. 11:95-101.

52. Wijkstrom, M., et al. 2004. Islet allograft survival in nonhuman primates immunosuppressed with basiliximab, RAD, and FTY720. Transplantation. 77:827-835.

53. Budde, K., et al. 2002. First human trial of FTY720, a novel immunomodulator, in stable renal transplant patients. J. Am. Soc. Nephrol. 13:1073-1083.

54. Kim, Y.M., Sachs, T., Asavaroengchai, W., Bronson, R., and Sykes, M. 2003. Graft-versus-host disease can be separated from graft-versus-lymphoma effects by control of lymphocyte trafficking with FTY720. J. Clin. Invest. 111:659-669. doi:10.1172/ JCI200316950.

55. Matsuura, M., Imayoshi, T., and Okumoto, T. 2000. Effect of FTY720, a novel immunosuppressant, on adjuvant- and collagen-induced arthritis in rats. Int. J. Immunopharmacol. 22:323-331.

56. Fujino, M., et al. 2003. Amelioration of Experimental Autoimmune Encephalomyelitis in Lewis Rats by FTY720 Treatment. J. Pharmacol. Exp. Ther. 305:70-77.

57. Fu, F., et al. 2001. FTY720, a novel immunosuppressive agent with insulinotropic activity, prolongs graft survival in a mouse islet transplantation model. Transplant. Proc. 33:672-673.

58. Okazaki, H., et al. 2002. Effects of FTY720 in MRL$1 \mathrm{pr} / 1 \mathrm{pr}$ mice: therapeutic potential in systemic lupus erythematosus. J. Rheumatol. 29:707-716. 